\section{Kennard Principle}

Bradley Axelrod and Christian Schutte

John D. Dingell VA Medical Center, Psychology

Section (11MHPS), Detroit, MI, USA

\section{Definition}

The recently disproven assumption that children recover more rapidly than adults suffering from the same type of brain lesion.

\section{Current Knowledge}

Initially proposed by Margaret Kennard in 1936 when studying primates, she found that motor impairment from unilateral lesions to the motor cortex was less severe in infants than in adults. This theory was generalized to humans in claiming that children would sustain less impairment and would recover more rapidly than adults if both sustained brain injury.

The initially widely accepted principle loses credibility as it was discovered that children with diffuse impairment did not recover more rapidly than their adult counterparts. Similarly, very young children did not recover as quickly as elderly adults did. In fact, younger children have greater difficulty with recovery of functions and have more developmental delays than older children. Prognosis for recovery is associated with existing cognitive skills as a foundation. Those abilities which have not yet been achieved will be delayed in acquisition following neurological injury.

The theory continues to be accepted by many clinicians, despite significant research which has demonstrated that age is unrelated to prediction of recovery from brain injury.

\section{Further Readings}

Duval, J., Braun, C. M. J., Montour-Proulx, I., Daigneault, S., Rouleau, I., \& Begin, J. (2008). Brain lesions and IQ: Recovery versus decline depends on age of onset. Journal of Child Neurology, 23(6), 663-668.

Webb, C., Rose, F. D., Johnson, D. A., \& Attree, E. A. (1996). Age and recovery from brain injury: Clinical opinions and experimental evidence. Brain Injury, 10, 303-310. 